University for Business and Technology in Kosovo

UBT Knowledge Center

Oct 28th, 2:00 PM - 3:30 PM

\title{
Lecture notes in social science: Author's instruction for the education of young generation to UBT Conference topic: Pedagogical dilemmas in the process of education of the young generation
}

\author{
Veton Zejnullahu \\ University for Business and Technology, veton.zejnullahu@ubt-uni.net \\ Denis Celcima \\ Universiteti Aleksander Moisiu, den_english@yahoo.it
}

Follow this and additional works at: https://knowledgecenter.ubt-uni.net/conference

Part of the Education Commons

\section{Recommended Citation}

Zejnullahu, Veton and Celcima, Denis, "Lecture notes in social science: Author's instruction for the education of young generation to UBT Conference topic: Pedagogical dilemmas in the process of education of the young generation" (2017). UBT International Conference. 122.

https://knowledgecenter.ubt-uni.net/conference/2017/all-events/122

This Event is brought to you for free and open access by the Publication and Journals at UBT Knowledge Center. It has been accepted for inclusion in UBT International Conference by an authorized administrator of UBT Knowledge Center. For more information, please contact knowledge.center@ubt-uni.net. 


\title{
Lecture Notes in Social Science: Authors' Instruction for the Education of Young Generation to UBT Conference Topic: Pedagogical dilemmas in the process of education of the young generation
}

\author{
Veton Zejnullahu, Denis Celcima \\ UBT-Higher Education Institution, Lagjja Kalabria, 10000 n.n., \\ Prishtina, Kosovo \\ Universiteti Aleksander Moisiu \\ veton.zejnullahu@ubt-uni.net,den_english@yahoo.it
}

\begin{abstract}
Not intentionally I do start with the teachers. We look at the basis of the study and the reaction at the core of psychology, with the need to apply its norms to organize our consciousness. Inside the protective activity against aggression in psychic behavior, "we must give the possibility of existence and safe development". We are the ones who have to appreciate the matter, because in our hands and minds the nation's future passes. Have we found the right line of human behavior in harmony with our social life and are we able to persuade this delicate age to recognize and accept their mistakes and beyond, to tell them what are the ways which harmonize individual relationships with the social environment? Here we try to give some explanation of possible ways for teens and youngsters, announcing a discussion invitation for all those who think they should give advice and recall in any case that "the golden word - take care" does not mean distrust on a generation , it is not about ignoring their age, skills and intellect, but is a "defensive step" towards "anti-virus screen" against the "amorous" fog. Because of their age, why should they stay away from the challenges and not try to succeed. Mistakes in practical study may results costly, but the mistakes in choosing the way of life "can result risky for human life and future." Our goal should be persistent to achievement
\end{abstract}

Keywords: Psychological dilemma, safe development, youngster nature, teaching process

\section{Interduction.}

Between antiquity and tradition, the transition to postmodern change brought.

The transition to new forms of progress, against the traditional ones, is not at all a consequence of the disappearance of the tradition of mass education, but the formation of new types, from the oldest and most inevitable, to the most favorable models of modern times; not only as a result of the new conditions of life and the environment, but also as a new trend of logical reasoning on the field of psycho-pedagogy.

This realistic trend is marking the end of harmony among individuals in the antiquity as prominent groups with the victims, the consequences, their effects, and the beginning of the new era of changes in the world of ideas - understood as a later end to resumption. The difference is obvious because there are exchanges of values between them: 
* firstly, preserved existence,

* secondly, foretell with a solution the end of their mystification.

Derived from philosophy, secondary divisions for pedagogy such as; metaphysics, epistemology, axiology, logic, in harmony with the sciences of nature, ontology and the seven aristotelian categories, constitute the basis of knowledge, defined as thought or reasoning.

- Metaphysics has given knowledge and pedagogy the nature of being, the reality and the origin of the world structure. As we perceive the reality and accuracy of knowledge - it has divided the individual into realistic, idealistic and relativistic.

* Epistemology, studies the nature and origin of knowledge, as well as attempts to answer questions: how do people learn, what is true, what is the value of knowledge. It is closely related to methodology, learning methods of knowledge. According to epistemological research, knowledge is gained in several ways: through perceptions, experimentation or praxis, logical reasoning, and scientific research. Epistemology dictates the paradigm that "perception is the sole source of knowledge". From this we reach a completely realistic ground:

knowledge comes from the senses, it is elaborated on the individual's brain, it gives excuses and judgments through spoken and written language.

* We have reached the core of pedagogy. The question: what is of value in knowledgeconstitutes the third dimension of pedagogical philosophy.

* Axology, gives the dimension of pedagogical knowledge, it studies their values and connections with human actions as they affect the way of behavior and way of life. The axiological concept relies on the acceptance of the existence of values, regardless of the existence of human being and determination, as relative readmission, of values according to the interests, perceptions or desires of each individual. In a Platonic, ethical and aesthetic dualism, axiology sets standards of conduct, criteria, the way of orientation and direction of our lives.

Revision of the past, its effects on the present and the future of the human being, is the subject of pedagogic aesthetics. Closely related to the standards of modern living and electronic time, aesthetic axiology makes a special contribution to education and training programs in the fields of fine music, literature and arts. So:

* Why did we handle these methodological elements in the essence of pedagogical philosophy, influenced by antiquity too?

* What motivates and encourages our daily life, is this more than a pedagogical value?

* Which remains the essence of the distinction between the two times?

\section{Impacts on Albanian Education and Pedagogy.}

An analogy and apology of the time makes up specific scientific research for everything useful for life. In this context, the particular aspects of pedagogical history are major efforts;

* the pure heritage of the Albanian language,

* the opening of primary schools, 
* Creating texts, programs,

* the model of teacher and pedagogue of Albanian language and culture during the National Renaissance period,

* During Albania's foreign invasions,

* elements of partisan school discipline

* finally a total passion - for the revolution of the school - in the field of education, art and culture throughout the totalitarian system period.

Historically, in the Albanian pedagogical education system, legal and methodological influences have been influenced by the schools of invading states and then, after 1944, the introduction of a mass education system to combat illiteracy without saving the ideology of the school. To complement the unfolded dimensions of pedagogy and its component elements are of interest:

* methodologies and methods applied by the Turkish school - to engage the new generation of language and pedagogy of the Ottoman Empire;

* Studying the patriotic and regenerative tendencies and great tendencies of patriot teachers - in the creation of patriotism and the great desire for the mother tongue;

* a comparative technical kind of time in the tendencies of the educational and pedagogical system of Italian education, in the introduction of pedagogical elements stylized with the images and civilizations of a war empire.

- Creating a national education system, aiming at mass education, against the consequences of conquest and the presence of illiteracy.

* Impacts of the Eastern education system from the former communist countries, especially the Russian, up to 1961, due to the education of the pedagogical corps and various fields abroad. of Pedagogic experiences in the period of democratic change; in particular, new developments in the classification of public-private schools, the introduction of different systems of education in dictatorship - the Bologna system, the master and doctoral procedures, the levels internally and internationally, the recognition of the diploma, the labor market, the return of foreign intelligence in the interest of the needs of the country have influenced the perfection of the education system

\section{Culture and Morality, the essence of the pedagogical philosophy of teaching and educating the younger generation.}

We can not penetrate the infinite spaces of education of the younger generation, without regard to some psychosocial and philosophical limits, which are the expression of the thought dominated by the pedagogical body and the students. Einstein in his time would write: "It is the highest art of the teacher to awaken joy in expressing and creative knowledge." And if we talk about teachers, we can not appreciate this disconnected from the reality in which they undergo their training in practicing the profession.

Politics and philosophy of morality are the path to the formalization of knowledge and intellect. The philosophical concept of pedagogical knowledge does not allow their deformation at all. In addition to special ones, the generational roles and their inherent combination play a negative role. "A poorly educated kid is a lost child." [John. F. Kennedy]. 
The culture of communication with society is articulated to the political elite and the elite of speech and writing. If the political elite represents the grouping of power, the elite of speech and writing represents a broader spectrum, the basis of which is the intelligence that exercises the right of profession in all fields of creativity and pedagogy.

Unfortunately, we must admit that the analysis of the political elite in the formal aspect of the information on the conditions for development and reformation of the education system today fits the social time and social category with all the negative phenomena that do not pass without attacking the pedagogical teaching group and the new generation of students.

The fundamental proof of the exercise of pedagogical law in the face of civic freedom is the manifestation of distinct discourse between the institutional and social groups of the society, connected and dependent upon one another. It is precisely social groups that do not have the real power in front of state institutions. Built on the complexity of the interests from the inside and outside, the models we have created today within the educational system of education follow their gradual path, but with imperfect deficiencies.

\section{Psycho-pedagogic dilemmas in the teaching body.}

The social movement with a predetermined object of the economic model that today dictates and remodels democracy in the function of education, does not leave out the influence of the student generation, who are part of the process of social transformation. Within these social movements, the forms of education and academic formation that have a direct impact on lifestyle and the transformation of thinking, unlike the reflections of power and governance, are outlined and introduced.

The education system is exposed to the decisions of the political power, present in the educational system through reform programs at the national level. Reform in the education system has consumed the imposed political time, has often risen the public reaction and protest, facing in the noisy limits with the unstoppable institutional stoicism. Often it is attempted to transform social action into action with political influence, diluting the pedagogical bodies with zeal, dedication, and awareness in the process of student education.

Under fragmentation conditions, pedagogical bodies often remain "betrayed", unsupported, gradually losing in its qualitative spectrum its characteristic peculiar features in terms of the practice of academic education and education.

The distinction of the phenomenon as a whole, increases the level of individual and collective disturbance, for "common concern issues", which are the result of the imposition. The most diligent servants, the cause of politicization, the passions and the instigators of the reaction process, have partially fallen within the limitations of silence and media confusion, shifted only on the media side, to maintain the workplace, continuing the rite of servility and of a mischievous pathology.

This situation, which mostly operates in the psycho-pedagogic plan, is necessarily part of the analysis, linking it to the essence of the presentation of the pedagogical body in function of its main mission in schools.

In the scientific analysis of the psycho-pedagogical character, there is no reason to overlook the concrete analysis of the action of institutional factors, which in consequence reports, give their impacts on education, increasing the dilemma in the pedagogical body, perhaps in an unmanageable dimension. The impact that the education system faces from the governing reform model is unconnected with the bad governance model chain. So far it is often thought that we have reached the limits of a strategy with risky strategies in the face of rising interest in the education of the younger generation. In this situation when the gang institutional operates, then why should not we be surprised?

In the most obscure political time, the passion of power turns into unethical and amoral rather than servility from the testimony of hatred or rejection. In Albania, philosophy, social and political doctrine and projects with special messages and functional geographic etymologies have 
infused endlessly. In the framework of the changes, articulation and mid-term and long-term plans are being articulated in transforming the education system, adding dilemmas to the pedagogical body. The dilemma is faced with the clarification of the law, the concepts of the rule of law, the principles of power, the dimensions of freedoms, altered with the laborious work towards the conceptualization of functional psycho-pedagogical methodology in the interest of education of the younger generation.

Essential treatment focuses on the logic of increasing the ability to act and judge according to moral and public principles in the face of the rule of law. The tendency to think positively toward contributions that complement the integrity of the pedagogical body is faced with the dilemmas that the system itself causes.

Part of the teacher's dilemma is this pattern of confession and appreciation, set in the encouragement of witnessing foolishness and frustration of thought to lawmakers, policy-makers, and decision-makers of power. In an undesirable dose, teachers here also look at the part of the guilt of Albanian society.

In their dual aspect, within an empirical and practical reality, the tendencies to offer a standard of education and the formation of the generation into democracy are the most competitive speculations and the most delusional illusions. A political game to introduce the right to vote at the age of 16 deepens the absurdity of constitutional, moral, and pedagogical walls.

\section{Should we extend the concept of pedagogy?}

The process of forming convictions and attitudes to life constitutes the major object of Pedagogy. According to the philosophical method, before we abandon the attitudes, we must reassess the method that has accompanied us to them, to encourage the correction of the mindset of prejudice. The process of knowledge formation, achieving thoughtfulness, imagination, and understanding of everyday life have brought about polarizations that are useful, though not harmful and sometimes irreparable.

Pedagogy is science, it has as its object itself, the field of teaching and the relationship between educating and educating subjects; studies and processes the processes of education, training and fuller qualification of children, students and students through the elaboration and application of the most useful methods.

Pedagogy provides the necessary knowledge and encourages scientific research to find new methodologies and methodologies. Creation without difficulty is worthless and unable to resist in time. Created with difficulty and judged "right", it must be preserved and confronted against all others. The basis of education and training is the discipline of the widest program processing, the increase of the load in accordance with;

* the level of theory,

* processing technology,

* Mass communication

* as well as the introduction of scientific news.

Method deformities and deviations from scientific debates testify;

* lack of tolerance,

* the luster of the intellect

* extreme conceit. 
The sincerity of conscious, altered or modified statements - as an element of a classical maturity process of intellect and intelligence - has been associated with dualistic criticisms of important public issues that have not been able to change the intellectual being of many teachers. To date, in the views of empirical, metaphysical and scientific experience, nothing has been perceived to be changed. Of course, this can not be the case in the future.

\section{The philosophical concept of pedagogy is unavoidable by philosophers, methodological criteria and scientific disciplines.}

"The gift of freedom is a gift of love". Love for knowledge, the first attempt to discover the nature of the world and of human being, belongs to philosophers and minds. Seeking nature, in trying to improve life and master the Earth, bright people are devoted to knowledge and culture. What is real, how can we know it, how to reason together on this concept - are some of the questions. Even though in empirical models, along the educational paths to the present day, word and writing, the methodology of learning and knowledge gaining, the ways of exchanging ideas, the methods of thought analysis, the gradual transition of concepts towards scientific truths and - the most essential - the method of understanding and judging knowledge to and from each individual, has been the major goals of peoples and nations. They belong to the all-round lining of civilizations and historical civilizations.

The historical curriculum of the pedagogical system in Albania, of course, is not the case today. The existent has been misused and distorted by leaders of institutions destined for ministry in the interest of civic and professional consciousness with retaliatory motives to the past system, forgetting the legitimacy of right and truth. Faced with Culture and Morality, the pedagogical bodies have been educated not to submit to mediocrity and ignorance, respecting the free thought and the human spirit without which education would not be called such.

\section{Some interpretations of the philosophy of pedagogy.}

They are similar and differentiated, particularly in defining the basic purpose of education, school and assessment of knowledge acquisition methods.

Knowing and applying the standards of education - education in the education system, the ways of formulating convictions and judgments, as well as the practical paths of knowledge for the young generation, necessarily require knowledge and understanding of philosophy - love for knowledge.

As a search for Life and Man, Philosophy, and within it, the Philosophy of Education continues to retain the right to research on consciousness, truths, falsehoods, relativity of the phenomenon or phenomenon, linking newly discovered elements in rational ways, modern and in their logical entirety. From centuries-old applied forms, it is remodeling the Human Being, in harmony with nature, ideas, and social impurity, even by feeling imagined in what disorders of Postmodern Time.

The modern pedagogical model can not be taken away from the philosophical feats of the time. In ancient pedagogical knowledge, Socrates, the philosopher of Ancient Greece, is the most unattainable. Through its peripatetic pedagogy, to be fair and virtuous, and to the question-answer system, at three levels of completion and reasoning, it remains the model of Modern Pedagogy. "... Evil stems from the fact that man is wrong about the matter of good." [Socrates].

The inclination and the criminal tendency of the individual or group is billed to the misunderstanding of society as to how evil and evil arise. For any extreme case, the preventive mechanism unduly eliminates the precious element of emotion, passion, delusion and ... belief. Within them, pedagogy conceives the word and the work. The first provides for dominance of formative - educative and individual; while the second, in the face of the socio-economic standard, deserves that pleasure and scientific respect. 


\section{What do teachers need to know about the philosophy and method of pedagogy?}

The harmony of knowledge, language and culture has been the most attacked by everyone and without realizing the consequences; in the worst case, consciously and in old forms. Logic is more decisive in pedagogical philosophy. It has a specific object of reasoning.

While Epistemology has defined reasoning as a way to gain knowledge, logic has defined the rules of reasoning. Through its three existential forms: formal, mathematical and dialectal logic, it channels the subjects into the didactic fret of quantitative passages in qualitative passages, between the general, the particular, and vice versa. Thus, empirical knowledge walks towards life's worthy truths. The following elaborations in the philosophy of pedagogy have not avoided the confusing conflicts between them and respect for the categories or criteria of the word. In these rubles, "the role of Plato is stimulating, and his idealism finds expression in the question: what is justice, wisdom?" He lists the hacking of human psyche; intellect, will, and desire, in conflict with one another to control human behavior. Likewise, Aristotle "invented the spiritual abandonment and in a practical, practical way, clarified the communicative relationship of the healthy body with the emotions controlled by consciousness." Among them lies virtue, still constitutes the pedagogical paradigm of any teacher, pedagogue or master of scientific research.

In order not to abandon their syncretic essence, today's studies and applications are focused on the needs of human nature, such as the difference between the image unit, the way of life and the encounter with the psychic life, seeking answers not only to physiological needs but even in being in a relationship with the social environment, with the impetus, constraints, responsibilities of education and labor market environments. Certainly, there is a dictated relationship between the subjects and the kingdom of their inclinations to prepare the character and personality necessary for life.

Need or constraint to avoid loneliness, unwanted imposition, lack of opportunity or isolation from the rest, similar and unequal, do not induce the subject [pupils, students, teachers, pedagogues] to plan and perform actions of an individual character. Living separately and in inactive forms creates mental disorders, they also imply the performance, primarily or necessarily, of harmful and unnecessary psychological actions. This situation that has to do with the philosophical understanding of the essence of psycho-pedagogy increases the teachers' dilemma about the future in educating the younger generation.

At the time of the set of festive days, or of the obligation of institutional presentation of reality, the figures appearing are astonishing and frightening. The People's Advocate reports shock. Data from humanitarian, non-governmental organizations in the field of education, social affairs, family, criminality, school dropouts, drug addiction, domestic violence and parents, increased contingent of beggars, robbers, increased number of children out of family care, blood feuds, outpatients, drug distributors, are as exhausted as anyone who would ask the question: What generation are we preparing and how will the future of society in Albania!

\section{First Phase: Closer to psycho-pedagogical methodology}

At the pedagogical object, the enjoyment of pedagogical products and the pain in the case of poor outcome, have the same nerve-brain center - the brain. This is interesting for teachers. The argument is useful to stay as close to the object of the subject of accepted and justified pedagogy: 
* Dictation: as a moral crisis - the dependence and duty of service to the other, the elimination of alternatives, the closing of the paths, the imposition of constraints;

* Defeat of right: denial, refusal, crisis of national identity, etc.

* Remembering historical awareness: as an unforgettable part of nations and humanity as a drive for revenge and restoration of the right.

Not only the philosophical divisions, but also the accepted dimensions of pedagogical logic, have given the value and the profitability in the field of traditional, classical and modern scientific knowledge and research. This background - for phenomena, events, phenomena, trends, tendencies and tendencies - has value for the research model. Its dimensions, implied as the essence of the rationale to penetrate into incomplete and undetected secrecy, define the criteria of the model.

With the claim of the complex character of the science and subject of pedagogy or of the dilemmas presented by the teachers due to the high level of knowledge, the increasing demands of the socio - economic and scientific research market as well as the major regional and global concerns, created by unemployment, demography, ecology, inclusive actors in the subject of pedagogical study have responded to the educational process and have conducted research based on the criteria of the logical model of the time:

- Historical criterion, as speaking and expressive consciousness "... what has happened, what we have caused and what to expect ...";

* Multilateral, especially historical, educational, economic, cultural heritage [civilization, civilization] with the encouragement: "... who am, what do I seek, where to

* The idea-political criterion, in dictatorship, as the essence of introducing to others the overload of science and pedagogical subjects;

* In the democratic model, as the basis of reflection on them and themselves;

* In modern times and the predictions of a postmodern existence - as a logical and untypical mind in relationships within and outside the social environment;

* Specific criteria, such as distinctness and favoritism at a certain historical time;

* Global criterion as a national and regional standard, avoiding inferiority, indifference, formalism, selfishness, nationalism, anarchy ... etc.

Conceived in its entirety, the process of scientific research follows the theoretical - practical methodologies based on criteria of imagination, fantasy, communication, exchange and recognition. A statement is true if its opposite can not be proven. The old thinking method [hypothesis] does not fit today's stage of development.

Pedagogy is a stimulant of emotions, creating the desired contact with the educational environment, and the untiring willingness to know. This is one side of the scientific concept of Pedagogy for the Psychic of the Individual, the Group and the whole Society. 


\section{The second aspect: Increasing the role of the environment in the individual's psychic behavior.}

An inevitable interdependence! The relationship of the individual with the school and the society is not sustainable, it is driven by the socio-economic interest. School and society create value for it, encourage passion and anxiety about the future. Society dictates in the formulation of educational programs, according to the course of progress it orientates its necessities and needs for the future. How will the balance be between them? This will stimulate further research.

The high level of knowledge and the rapid rate of information exchange and technology development, allow broad communication and ownership. These have erased or confused the divisional lines of science with philosophy, thus facilitating the mission of scholars. Although the areas of Word and Scripture are widened enough and abundant, the model of positive thinking continues to exist together with its own categories, to modify the personality of every scholar and philosophy, to itself with little change. In negative patterns, the lectures "I suppose, I have for printing, in my opinion ..." place the authority of the morality of knowledge on the limits of misery.

Today's individual does not sacrifice the civilization of his time. Real identity has in itself a change. No one should feel ashamed or afraid of the level of knowledge, he should be concerned about the lack of will, to learn and understand throughout life.

\section{Conclusion}

Thought dominated by insoluble emotional conflicts and psychic behavior with a symptom of interest are being driven by the destruction of life. Psychoanalysts are twisted in their ability to make ends. Civilized behavior, anti-barbarianism and heresy have been tested.

The existence of social issues and the concern of society for the creation of younger generations - a qualified child at risk - constitutes the major objective of the philosophy of morality and pedagogical knowledge, the very essence of the dilemma accompanying the pedagogical body today. They will remain an inescapable thrust of the cultural, socio-economic progress of modern civilizations and civilizations. It is this reason that teachers today may think that they are giving a reality in the gap of ideas

There are many reasons to think so, as the unification of the morality of the doctrine of integration, under conditions prepared to cope with changes in the education system, is gradually destroying the national identity. He has been subjected to the experimentation of methods, forms, or tools to elaborate and stylize faith, opinion, lifestyles, the tried and tested ideas in the historical overcoming of civilized peoples, to recreate historic state heritage.

Teachers are well aware that reading, writing, speaking, thinking, and mathematical calculations develop to people the skills necessary to gain knowledge, but modern time has shaped this classroom teacher-student, technology with communication capacities and processing opportunities in a short time. The dilemma: Are we able to withstand this situation that carries within the contradiction of the time?

In reality, to accept these changes ideas are not lacking. They come naturally from the experiences and failures of the system of governments, which when they have begun to start everything from scratch and do a good thing, in fact often have done some bad things. With the same totalitarian logic of isolation, repression and lack of freedom of thought, the inclusive and exclusionary doctrines of moral philosophy are adapting and adapting to a new concept of culture, without affecting the inevitable empire of the cult of traditional and historical prejudices relations between nations and peoples. 
Apparently, we must admit that, in the face of the pressure of change and the control and memory institution, the "ignorance of the past" has been proclaimed the right to recognize and master the "lacking knowledge".

\section{References:}

1. Myra Pollack Sadker, David Miller Sadker, Teachers School and society .Published, Random House New York viti 1988; Published "Eureka", Tiranë 1995; f. 220

2. Myra Pollack Sadker, David Miller Sadker, Teachers School and society .Published, Random House New York viti 1988; Published "Eureka", Tiranë 1995; f. 222

3. Albert Ajshajn, Life and work, Published Tiranë, 2003, faqe 24

4. Myra Pollack Sadker, David Miller Sadker, Teachers School and society .Published, Random House New York viti 1988; Published "Eureka", Tiranë 1995; f. 234

5. . Myra Pollack Sadker, David Miller Sadker, Teachers School and society .Published, Random House New York viti 1988; Published "Eureka", Tiranë 1995; f. 223

6. Myra Pollack Sadker, David Miller Sadker, Teachers School and society .Published, Random House New York viti 1988; Published "Eureka", Tiranë 1995; f. 223

7. Myra Pollack Sadker, David Miller Sadker, Teachers School and society .Published, Random House New York viti 1988; Published "Eureka", Tiranë 1995; f. 221

8. Myra Pollack Sadker, David Miller Sadker, Teachers School and society .Published, Random House New York viti 1988; Published "Eureka", Tiranë 1995; f. 223

9. Myra Pollack Sadker, David Miller Sadker, Teachers School and society .Published, Random House New York viti 1988; Published "Eureka", Tiranë 1995; f. 223

10. Myra Pollack Sadker, David Miller Sadker, Mësuesit Shkolla dhe Shoqëria, Botim Random House New York viti 1988; Botim në shqip shtëpia botuese "Eureka", Tiranë 1995; f. 223

11. Myra Pollack Sadker, David Miller Sadker, Mësuesit Shkolla dhe Shoqëria, Botim Random House New York viti 1988; Botim në shqip shtëpia botuese "Eureka", Tiranë 1995; f. 223

12. Myra Pollack Sadker, David Miller Sadker, Mësuesit Shkolla dhe Shoqëria, Botim Random House New York viti 1988; Botim në shqip shtëpia botuese "Eureka", Tiranë 1995; f. 221

13. Myra Pollack Sadker, David Miller Sadker, Mësuesit Shkolla dhe Shoqëria, Botim Random House New York viti 1988; Botim në shqip shtëpia botuese "Eureka", Tiranë 1995; f. 218

14. Myra Pollack Sadker, David Miller Sadker, Mësuesit Shkolla dhe Shoqëria, Botim Random House New York viti 1988; Botim në shqip shtëpia botuese "Eureka", Tiranë 1995; f. 224 